\title{
Knockdown of the C. elegans Kinome identifies Kinases required for normal protein Homeostasis, Mitochondrial network structure, and Sarcomere structure in muscle
}

\author{
Susann Lehmann, Joseph J Bass and Nathaniel J Szewczyk
}

\begin{abstract}
Background: Kinases are important signalling molecules for modulating cellular processes and major targets of drug discovery programs. However, functional information for roughly half the human kinome is lacking. We conducted three kinome wide, $>90 \%$, RNAi screens and epistasis testing of some identified kinases against known intramuscular signalling systems to increase the functional annotation of the C. elegans kinome and expand our understanding of kinome influence upon muscle protein degradation.

Results: 96 kinases were identified as required for normal protein homeostasis, 74 for normal mitochondrial networks and 50 for normal sarcomere structure. Knockdown of kinases required only for normal protein homeostasis and/or mitochondrial structure was significantly less likely to produce a developmental or behavioural phenotype than knockdown of kinases required for normal sarcomere structure and/or other sub-cellular processes. Lastly, assessment of kinases for which knockdown produced muscle protein degradation against the known regulatory pathways in C. elegans muscle revealed that close to half of kinase knockdowns activated autophagy in a MAPK dependent fashion.

Conclusions: Roughly 40\% of kinases studied, 159 of 397, are important in establishing or maintaining muscle cell health, with most required for both. For kinases where decreased expression triggers protein degradation, autophagy is most commonly activated. These results increase the annotation of the $C$. elegans kinome to roughly $75 \%$ and enable future kinome research. As 33\% of kinases identified have orthologues expressed in human muscle, our results also enable testing of whether identified kinases function similarly in maintaining human muscle homeostasis.
\end{abstract}

Keywords: Autophagy, C. elegans, Kinome, MAPK, Mitochondria, Muscle, Protein degradation, Proteostasis, Sarcomere

\section{Background}

Kinases are enzymes that alter proteins and lipids by phosphorylation, the addition of a phosphate group. This modification can influence a protein's steric structure and cause changes in protein-protein binding affinities and enzyme activities [1]. Kinase encoding genes constitute $2 \%$ of the human genome making kinases one of

\footnotetext{
* Correspondence: nate@alumni.cmu.edu

Medical Research Council/Arthritis Research UK Centre for Musculoskeletal Ageing Research, University of Nottingham, Royal Derby Hospital, Derby
} DE22 3DT, England

the largest protein families, which is termed the kinome. Kinases also appear to play a major role in modulating cellular processes as roughly $30 \%$ of intracellular proteins are phosphate bound at any given time [2]. Accordingly, kinase inhibitors account for a large part of drug discovery programs in the pharmaceutical industry. Roughly 150 inhibitors of 42 well validated kinase targets are currently being tested in clinical trials [3]. These 42 targets constitute only about $8 \%$ of the kinome. Although further progress is being made in identifying the function of already well-known kinases in the regulation of 
specific cellular processes, $50 \%$ of the kinome remains largely uncharacterized [3]. Thus, we lack an understanding of the complexity of process modulation by a considerable part of the kinome. In this study, we took a multi-level functional genomics approach to identify kinases required for normal function of individual and multiple processes within a single tissue in vivo.

To accomplish this work we employed the soil nematode Caenorhabditis elegans as it is a convenient multicellular organism for systems biology research [4]. The C. elegans kinome contains 438 kinases which have been assigned to 168 subfamilies [5]. Of these subfamilies, 153 are shared with the human kinome [5]. This conservation suggests that $81 \%$ of human kinases have homologues in C. elegans. Despite knowledge of these kinase encoding genes, several functional genomic screens looking at the developmental and behavioural effects of RNA interference against each gene in the genome [6,7], and the effort to knock out every gene in the genome [4], the C. elegans kinome still appears understudied. A search of the C. elegans database, www.wormbase.org [8], reveals that only roughly $60 \%$ of all kinase-encoding genes have been assigned a genetic or RNAi phenotype.

As several past studies failed to detect a developmental or behavioural effect of RNAi against kinase encoding genes, we studied the effect of kinase knockdown by RNAi on subcellular processes within muscle. We chose muscle as it is a highly regulated, adaptable tissue that responds to environmental inputs such as use and nutrition in a balanced fashion in order to maintain whole body homeostasis. Additionally, identification of new therapeutic targets for modulating muscle homeostasis is desirable as inability to maintain muscle can become a major health concern. Severe wasting of muscle is associated with conditions such as disuse, starvation, several diseases, and inevitably occurs in the elderly [9].

To study the kinome requirement for establishing and maintaining cellular homeostasis, we picked two processes that occur in all cell types, protein homeostasis and mitochondrial dynamics, and one process that is specific to muscle, sarcomere assembly and maintenance. We obtained previously utilized RNAi constructs and examined the effect of knockdown of each kinase upon each process in muscle. We established that 159 kinaseencoding genes, $40 \%$ of the C. elegans kinome screened [5], appear to influence sub-cellular processes within muscle. Of these 159 genes, $64 \%$ appear to be required to maintain homeostasis of fully differentiated adult muscle, $32 \%$ appear to be required for multiple sub-cellular processes, and $50 \%$ have identified human orthologues $[5,10]$ of which 53 are reported to be expressed in human skeletal muscle [11] (Additional file 1). This quantifies the kinome requirement for normal development and maintenance of a single tissue in vivo and assigns RNAi phenotypes to 51 kinases for which no phenotype was previously assigned by genetic or RNAi approaches. Similar to a past study of genes known to influence muscle function [12], we found that individual kinases were most frequently required for proper protein homeostasis and least frequently required for proper sarcomere structure. This suggests that past studies aimed at understanding genomic control of sarcomere structure [13,14] have only begun to uncover the complexity of genomic control of muscle.

To better understand the nature of the kinome requirement for maintenance of muscle homeostasis, we performed epistasis tests with kinases whose knockdown triggered muscle protein degradation against known proteolytic signalling mechanisms in $C$. elegans muscle. While knockdown of individual kinases triggered different types of protein degradation, mitogen activated protein kinase MPK-1 dependent autophagy was triggered in close to half of the knockdowns that triggered degradation. Our results not only contribute to the global understanding of the kinome, they may also lead to the discovery of new therapeutic targets for the modulation of muscle homeostasis.

\section{Results}

\section{Kinases required for normal protein synthesis and} degradation in muscle

Modulation of global protein synthesis, degradation, or both, can lead to either cellular hypertrophy or atrophy. In multicellular organisms these processes must be regulated such that adjacent cells can grow or shrink together. For example, adult $C$. elegans muscle and hypodermis undergo coordinated hypertrophy [15]. Similarly, regulation is required so that one tissue does not receive inordinate nutrients. For example, tumours circumvent such regulation. In man, several extramuscular signals are known to affect protein homeostasis in muscle and are thought to do so via a number of mechanisms, rather than via a single mechanism [16]; however in many cases the transducing signals or mechanisms are not known or are inadequately understood.

To study the effects of altered kinase signalling on cytosolic protein homeostasis, termed proteostasis, we used a well-established C. elegans model $[17,18]$. In this model a myosin heavy chain gene promoter and enhancer drive the expression of a lacZ reporter transgene to report on alterations in muscle protein synthesis. As $\beta$-galactosidase synthesis stops when animals reach adulthood and the $\beta$-galactosidase remains stable for at least 72 hours [17], loss of $\beta$-galactosidase in response to acute interventions indicates that degradation, not a reduction in protein synthesis, is occurring in fully differentiated adult muscles. Chronic RNAi knockdown of 96 genes resulted in altered levels of $\beta$-galactosidase activity, suggesting that these genes are required for 


\section{A Proteostasis}

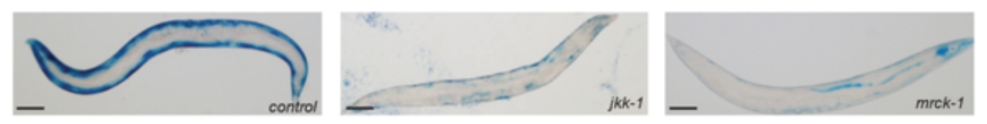

\section{B Chronic and acute effect Chronic RNAi Acute RNAi}

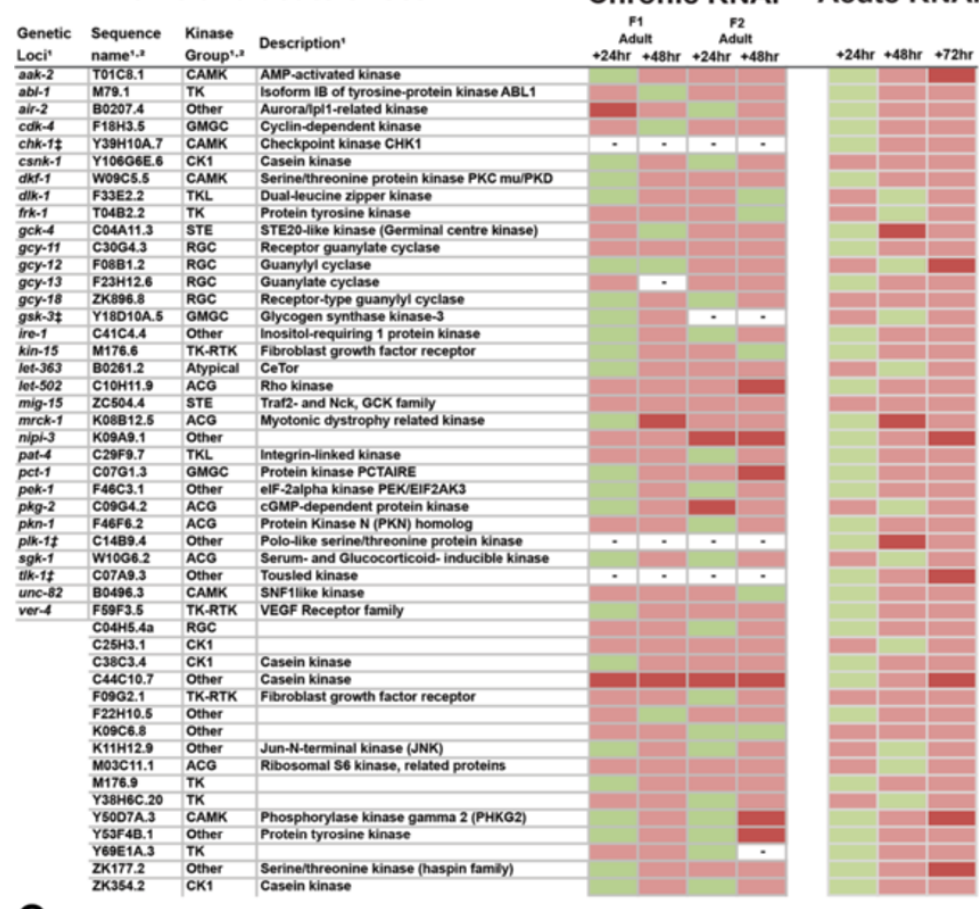

\section{Chronic effect only}

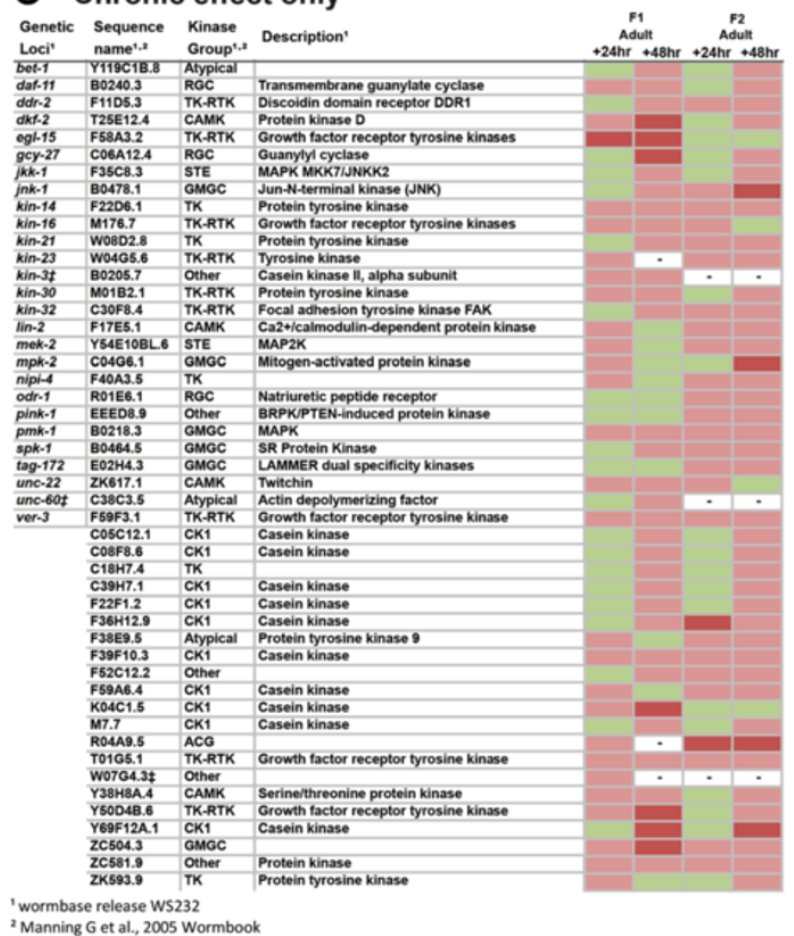

Figure 1 (See legend on next page.) 
(See figure on previous page.)

Figure 1 Kinases that appear to be required for normal muscle protein synthesis and/or degradation. (A) Sample images of normal $\beta$-galactosidase reporter staining (dark blue) in control, non-RNAi treated, PD55 animal (left) and RNAi treated animals showing decreased $\beta$-galactosidase reporter staining. RNAi treatments are indicated in the lower right corner. Scale bars represent $100 \mu$ m. (B) Kinases identified as required for normal lack of protein degradation in muscle. Indicated RNAi treatments were conducted chronically and followed up acutely and scored for decreased $\beta$-galactosidase reporter staining, see materials and methods. Displayed are scoring data for each time point $(n=20-30)$. Green indicates staining not appreciably different from controls. Red indicates that at least $25 \%$ of scored animals displayed lighter/diffuse blue or lack of blue staining versus controls. Dark red indicates that at least $50 \%$ of scored animals displayed light/diffuse blue or lack of blue staining versus controls. (C) Kinases identified as required for normal protein homeostasis in muscle. RNAi treatments were conducted and scored as in (B) however the listed treatments produced a defect in the chronic screen but not the acute screen. - Indicates lack of data for a given time point. ₹ Indicates a treatment was classed as producing a lack of progeny in this screen.

proper regulation of protein synthesis and/or degradation (Figure 1). At least some of these 96 kinases are likely to be required for normal protein synthesis during development, for example EGL-15 which is required for proper muscle development [19], but further experiments are required to confirm to what extent genes identified in the chronic screen may regulate synthesis, degradation, or both. To determine if decreased levels of $\beta$-galactosidase activity could be accounted for by increased protein degradation alone, we knocked down the identified genes acutely. We also acutely knocked down genes for which a lack of progeny prohibited full analysis in the chronic screen. Using this approach we identified 48 kinases that appear to be required to prevent abnormal muscle protein degradation (Figure 1). Two of the 48 kinases, pat- 4 and unc-82, have recently been shown to be negative regulators of muscle protein degradation in C. elegans [15] and two, gsk-3 [20] and $s g k-1$ [21], are known to interact with insulin signalling which is also a known regulator of muscle protein degradation in C. elegans [22]. Thus, some of the results from the screen appear to validate our approach. As expected, several kinases without known phenotypes in mutants or in response to RNAi were found to be required for normal protein synthesis and/or degradation or required to prevent abnormal protein degradation (Additional file 1). Lastly, the identification of ire-1 and pek-1, which are well conserved regulators of the endoplasmic reticulum unfolded protein response [23] demonstrates that, as expected, some of the identified kinases act to maintain protein homeostasis not just in muscle, but in most tissues.

\section{Kinases required for normal mitochondrial network structure}

It is now widely accepted that mitochondrial networks are dynamic, undergoing morphological changes to maintain organelle homeostasis or to respond to the metabolic changes within the cell [24]. Advances have been made in determining the mechanisms of mitochondrial organellar quality control; it is however still unclear how mitochondria integrate multiple cellular signals into fission and fusion processes and to what extent mitochondria are self-regulated.

In order to gain insight into the kinome requirement for normal mitochondrial structure in muscle, we examined mitochondrial morphology in C. elegans containing mitochondrial localized GFP [25] (Figure 2). Chronic RNAi knockdown of 74 kinase encoding genes induced a fragmented mitochondrial network suggesting that these kinases are required for proper establishment and/ or maintenance of the mitochondrial network in muscle. Included within these 74 genes is pink-1, which encodes PTEN-induced putative kinase 1 , and which when mutated in Drosophila melanogaster is known to induce mitochondrial morphology defects in muscle as well as other tissues [26]. Utilizing a pink-1 knockout allele, see materials and methods, we confirmed that loss of function of pink-1 results in fragmentation of the mitochondrial network in muscle. To determine if disrupted mitochondrial morphology could be attributed to a kinase requirement for maintenance of the mitochondrial network in muscle we knocked down the identified kinase encoding genes acutely in adults. We also acutely knocked down genes for which a lack of progeny prohibited full analysis in the chronic screen. Using this approach we identified 44 kinases that appear to be required for proper maintenance of the mitochondrial network in muscle (Figure 2). Within this set of 44 genes is kin-1, which is already known to be involved in the maintenance of mitochondrial networks [27]. As was the case with the screen for kinases required for protein homeostasis, the identification of known regulators of mitochondrial dynamics appears to support our approach and, as expected, several kinases without known phenotypes in mutants or in response to RNAi were found to be required for normal mitochondrial network structure (Additional file 1).

\section{Kinases required for normal sarcomere assembly and maintenance}

In addition to studying two processes that occur in most tissues, we studied the kinome requirement for a muscle specific process. For this we chose sarcomere assembly and maintenance, as the most recognized 


\section{A Mitochondrial network}
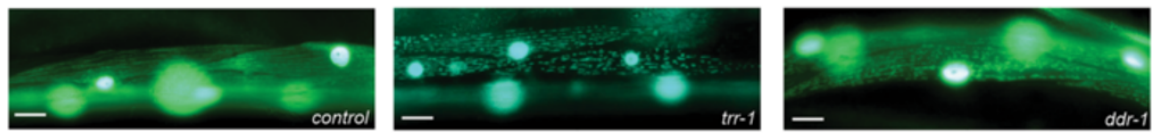

\section{B Chronic and acute effect}

\section{Chronic RNAi Acute RNAi}

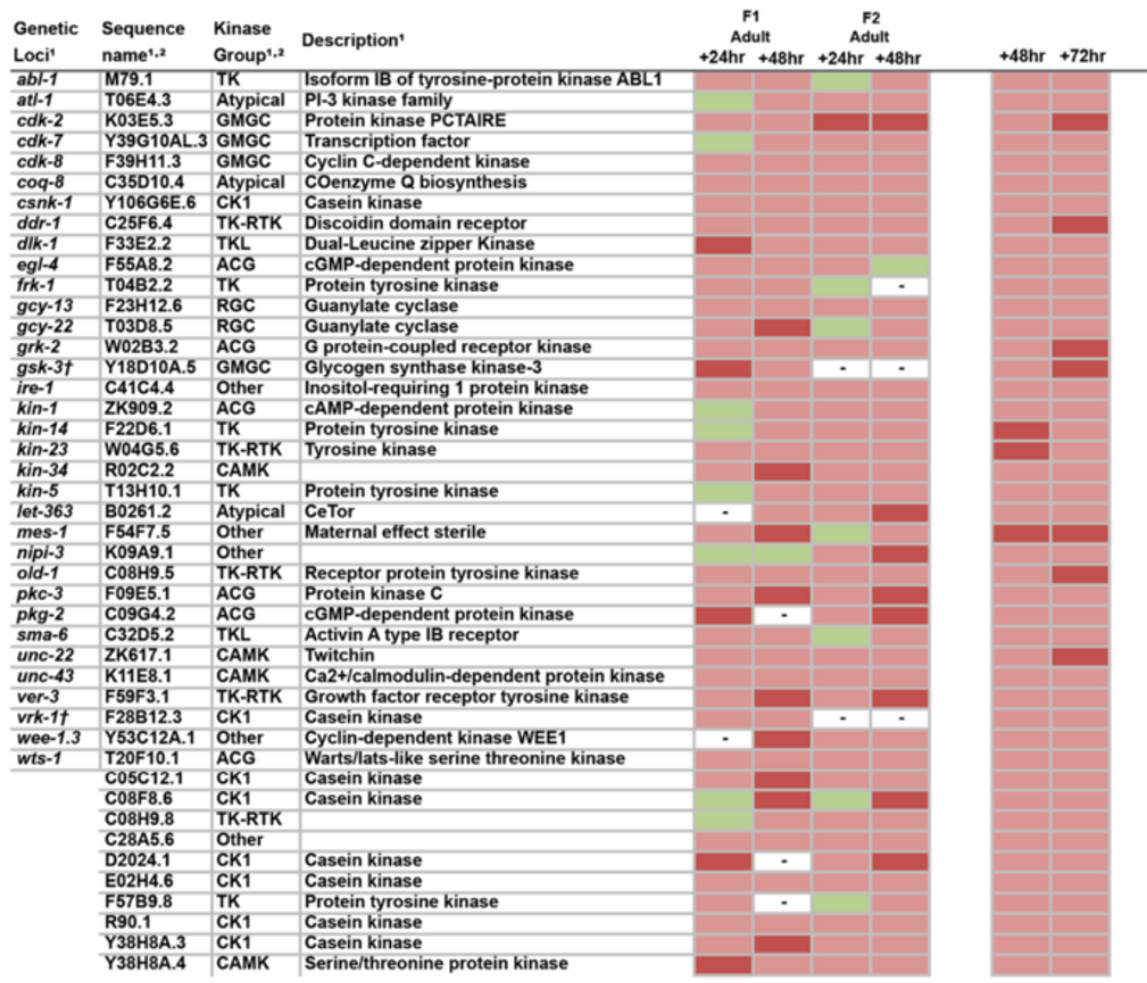

\section{Chronic effect only}

\begin{tabular}{|c|c|c|c|c|c|c|c|}
\hline $\begin{array}{l}\text { Genetic } \\
\text { Loci' }\end{array}$ & $\begin{array}{l}\text { Sequence } \\
\text { name' }{ }^{1,2}\end{array}$ & $\begin{array}{l}\text { Kinase } \\
\text { Group',2 }\end{array}$ & Description' & \multicolumn{2}{|c|}{$\begin{array}{c}\text { F1 } \\
\text { Adult }\end{array}$} & \multicolumn{2}{|c|}{$\begin{array}{c}\text { F2 } \\
\text { Adult }\end{array}$} \\
\hline aak-1 & PAR2.3 & CAMK & AMP-activated kinase & & & $+24 \mathrm{hr}$ & r $+48 \mathrm{hr}$ \\
\hline air-2 & B0207.4 & Other & Aurora/pl1-related kinase & & & & \\
\hline akt-2 & F28H6.1 & ACG & Serine/threonine protein kinase & & & & \\
\hline bet-1 & Y119C1B.8 & Atypical & & & & & \\
\hline cdtl-7 & B0285.1 & GMGC & Cdc2-related protein kinase & & & & \\
\hline$d k d-1$ & WO9C5.5 & CAMK & Serine/threonine protein kinase PKC mu/PKD & & & & \\
\hline dyt-18 & H01G02.2 & GMGC & Transcription factor & & & & - \\
\hline gcy-7 & F52E1.4 & RGC & Natriuretic peptide receptor & & & & \\
\hline grk-1 & F19C6.1 & ACG & G protein-coupled receptor kinase & & & & \\
\hline kin-16 & M176.7 & TK-RTK & Growth factor receptor tyrosine kinase & & & & \\
\hline$m o m-4$ & F52F12.3 & TKL & Protein tyrosine kinase & & & & \\
\hline pat-4t & C29F9.7 & TKL & Integrin-linked kinase & & & - & - \\
\hline pink-1 & EEED8.9 & Other & BRPK/PTEN-induced protein kinase & & & & \\
\hline$p m k-1$ & B0218.3 & GMGC & MAPK & & & & \\
\hline spk-1 & B0464.5 & GMGC & SR Protein Kinase & & & & \\
\hline $\operatorname{tag}-172$ & E02H4.3 & GMGC & LAMMER dual specificity kinase & & & & \\
\hline & C47D12.1 & Atypical & Histone acetyltransferase SAGA & & & & \\
\hline unc-82 & B0496.3 & CÁMK & SNF1like kinase & & - & & \\
\hline & B0218.5t & CK1 & Casein kinase & & - & - & - \\
\hline & C55C3.4 & TK & Protein tyrosine kinase & & - & & \\
\hline & F09C12.2 & GMGC & Mitogen-activated protein kinase & & & & \\
\hline & F39F10.3 & CK1 & Casein kinase & & & & \\
\hline & R02C2.1 & CAMK & & & & & \\
\hline & R04A9.5 & $A C G$ & & & & & \\
\hline & T08D2.7 & CAMK & Serine/threonine protein kinase Chk2 & & & & \\
\hline & T25B9.4 & TK & Protein tyrosine kinase & & & & \\
\hline & W06F12.3 & CK1 & Casein kinase & & 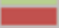 & & \\
\hline & W07G4.3 & Other & & & & & \\
\hline & Y111B2A.1 & GMGC & LAMMER dual specificity kinase & & & & \\
\hline & Y32H12A.7 & Atypical & & & & & \\
\hline
\end{tabular}

'wormbase release W\$232

${ }^{2}$ Manning G et al., 2005 Wormbook

Figure 2 (See legend on next page.) 
(See figure on previous page.)

Figure 2 Kinases that appear to be required for normal mitochondrial network structure. (A) Sample images of GFP labelled mitochondrial networks, and nuclei (large over exposed circles), showing normal mitochondrial network structure in control, non-RNAi treated, CB5600 animal (left) and RNAi treated animals showing disrupted network structure. RNAi treatments are indicated in the lower right corner. Scale bars represent $20 \mu \mathrm{m}$. (B) Kinases identified as required for normal maintenance of mitochondrial network structure in adult muscle. Indicated RNAi treatments were conducted chronically and followed up acutely and scored for loss of mitochondrial network organization, see materials and methods. Displayed are scoring data for each time point $(n=20-30)$. Green indicates networks not appreciably different from controls. Red indicates that at least $25 \%$ of scored animals displayed disrupted mitochondrial network structure versus controls. Dark red indicates that at least $50 \%$ of scored animals displayed disrupted mitochondrial network structure versus controls. (C) Kinases identified as required for normal mitochondrial network structure. RNAi treatments were conducted and scored as in (B) however the listed treatments produced a defect in the chronic screen but not the acute screen. - Indicates lack of data for a given time point. + Indicates a treatment was classed as producing a lack of progeny in this screen.

function of skeletal muscle is to enable body movement through the contraction and relaxation of many highly organized sarcomeric units. Additionally, as sarcomere structure is conserved from $C$. elegans through higher metazoans, $C$. elegans has become a well-established and validated model for the study of sarcomere structure and assembly $[28,29]$.

To examine the effects of kinase knockdown on sarcomere structure, we used animals expressing a myosin heavy chain GFP that localizes to the M-line of sarcomeres [30]. Chronic RNAi knockdown of 50 kinase-encoding genes induced disorganization or tears in the sarcomeric structure (Figure 3) suggesting that these kinases are required for normal sarcomere assembly or maintenance. $12 \%$ of these 50 genes are already known to be involved in the regulation of sarcomere structure. For example, pat-4, which encodes integrin-linked kinase, and which is part of the muscle attachment complex to the basement membrane [31] and unc-89 and unc-22 which encode the structural proteins obscurin [32] and twitchin [33], and which play a major role in the structural integrity of the sarcomeres. To determine if disrupted sarcomere structure could be accounted for by a kinase requirement for normal maintenance of sarcomeres, we knocked down these 50 kinase-encoding genes acutely in adults. We also acutely knocked down genes for which a lack of progeny prohibited full analysis in the chronic screen. Using this approach we identified $34 \mathrm{ki}-$ nases that appear to be required for proper maintenance of the sarcomeres (Figure 3). As was the case with our other two screens for kinome requirement for sub-cellular processes within muscle, the results of this screen confirm previous observations and identify several genes for which no phenotype was previously assigned (Additional file 1).

\section{Multiple subcellular defects are more likely to produce a developmental or behavioural phenotype}

Comparison of single vs. multiple defects within muscle following RNAi (Figure 4) revealed that kinases appear to be most frequently required to maintain proteostasis and least frequently required for normal sarcomere structure. This result is similar to a past RNAi screen of 159 genes previously known to influence muscle contraction [12].
However, in contrast to this past study, which found an overrepresentation of genes required for normal protein homeostasis, mitochondrial network structure and sarcomere structure, we found that the distribution of kinases required to maintain multiple processes within muscle was not significantly different from a normal distribution $\left(x^{2}\right.$, GraphPad Prism). However, there was significant enrichment ( $\mathrm{p}<.05, \mathrm{x}^{2}$, GraphPad Prism) of developmental or behavioural phenotypes amongst the genes for which RNAi produced defects in sarcomere structure and protein homeostasis and/or mitochondrial network structure (Figure 4, bottom three clusters of genes). Taken together, the results from our study and the past study [12] suggest that past genetic screens aimed at understanding genes regulating muscle function, usually contraction, are more likely to have identified genes that disrupt multiple subcellular processes within muscle than genes that disrupt a single process (NB 9 of the 10 kinases we identified in all three screens are well studied). The results also imply that the genomic control of the metabolic functions of muscle, such as protein homeostasis and mitochondrial energy production, are likely underestimated by past studies aimed at understanding the genomic control of sarcomere structure or function $[13,14]$.

\section{Lack of enrichment of any kinase group amongst kinases identified}

We assessed which kinase groups were represented by the genes identified in each of our three screens. A comparison of the number of kinases identified from each group versus the total number of kinases screened in each group revealed no statistically significant $\left(x^{2}\right.$, GraphPad Prism) enrichment of any kinase group. This lack of enrichment was observed in each screen and for the total set of kinases identified from all three screens (not shown).

\section{Epistasis testing of potential degradation-regulating kinases versus known signals}

We conducted epistasis tests to gain further functional insight into how some of the identified kinases are acting. Because there are well defined signals regulating 
A Sarcomere structure
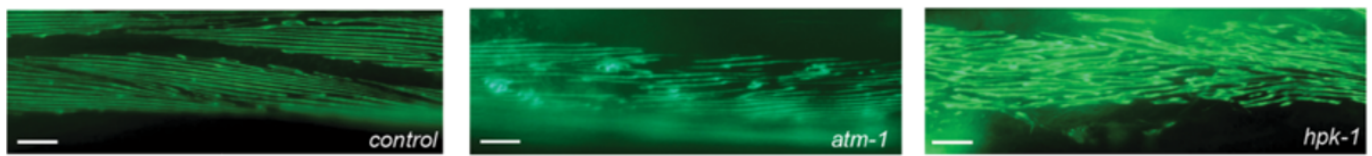

\section{B Chronic and acute effect}

\section{Chronic RNAi Acute RNAi}

\begin{tabular}{|c|c|c|c|c|c|c|c|c|c|}
\hline \multirow{2}{*}{$\begin{array}{l}\text { Genetic } \\
\text { Loci' }\end{array}$} & \multirow{2}{*}{$\begin{array}{l}\text { Sequence } \\
\text { name } e^{1,2}\end{array}$} & \multirow{2}{*}{$\begin{array}{l}\text { Kinase } \\
\text { Group' }{ }^{1,2}\end{array}$} & \multirow[t]{2}{*}{ Description' } & \multicolumn{2}{|c|}{$\begin{array}{c}\text { F1 } \\
\text { Adult }\end{array}$} & \multicolumn{2}{|c|}{$\begin{array}{c}\text { F2 } \\
\text { Adult }\end{array}$} & \multirow[b]{2}{*}{$+48 \mathrm{hr}$} & \multirow[b]{2}{*}{$+72 \mathrm{hr}$} \\
\hline & & & & $+24 \mathrm{hr}$ & $+48 \mathrm{hr}$ & $+24 \mathrm{hr}$ & $+48 \mathrm{hr}$ & & \\
\hline csnk-1 & Y106G6E.6 & CK1 & Casein kinase & & & & & & \\
\hline gcy-14 & ZC412.2 & RGC & Transmembrane guanylyl cyclase & & & & & & \\
\hline hpk-1 & F20B6.8 & GMGC & Dual-specificity protein kinase DYRK1A & & & & & & \\
\hline kin-21 & W08D2.8 & TK & Protein tyrosine kinase & & & & & & \\
\hline kin-26 & T06C10.6 & TK & Protein tyrosine kinase & & & & & & \\
\hline kin-3 & B0205.7 & Other & Casein kinase II, alpha subunit & & & & & & \\
\hline let-502 & $\mathrm{C} 10 \mathrm{H} 11.9$ & ACG & Rho kinase & & & & - & & \\
\hline lit-1* & W06F12.1 & GMGC & Nemo-like MAPK & $\cdot$ & $\cdot$ & $\cdot$ & - & & \\
\hline mek-2 & Y54E10BL.6 & STE & MAP2K & & & & & & \\
\hline nipi-4 & F40A3.5 & TK & & & & & & & \\
\hline pat-4* & C29F9.7 & TKL & Integrin-linked kinase & & & & & & \\
\hline pct-1 & C07G1.3 & GMGC & Protein kinase PCTAIRE & & & & & & \\
\hline pkc-3 & F09E5.1 & ACG & Protein kinase C & & & & & & \\
\hline plk-1* & C14B9.4 & Other & Polo-like serine/threonine protein kinase & $\cdot$ & $\cdot$ & $\cdot$ & - & & \\
\hline plk-2 & Y71F9B.7 & Other & Polo-like serine/threonine protein kinase & & & & & & \\
\hline plk-3 & F55G1.8 & Other & Polo-like serine/threonine protein kinase & & & & & & \\
\hline$p m k-1$ & B0218.3 & GMGC & MAPK & & & & & & \\
\hline$s g k-1$ & W10G6.2 & ACG & Serum- and Glucocorticoid- inducible Kinase & & & & & & \\
\hline spk-1 & B0464.5 & GMGC & SR Protein Kinase & & & & & & \\
\hline unc-22 & ZK617.1 & CAMK & Twitchin & & & & & & \\
\hline unc- -43 & K11E8.1 & CAMK & Ca2+/calmodulin-dependent protein kinase & & & & & & \\
\hline unc-82 & B0496.3 & CAMK & SNF1like kinase & & - & & & & \\
\hline unc-89 & C24G7.5 & CAMK & Guanine nucleotide exchange factor GNEF & & & & & & \\
\hline & C24G6.2 & TK-RTK & FGF/PDGF receptor & & & & & & \\
\hline & F11E6.8 & TK-RTK & Protein tyrosine kinase & & & & & & \\
\hline & R90.1 & CK1 & Casein kinase & & & & & & \\
\hline & T25B9.5 & TK & Protein tyrosine kinase & & & & & & \\
\hline & W01B6.5 & TK & Protein tyrosine kinase & & & & & & \\
\hline & Y38H8A.3 & CK1 & Casein kinase & & & & & & \\
\hline & Y38H8A.4 & CAMK & Serine/threonine protein kinase & & & & & & \\
\hline & Y43C5B.2 & TK & Protein tyrosine kinase & & & & & & \\
\hline & Y69E1A.3 & TK & & & & & & & \\
\hline & ZC581.9 & Other & Protein kinase & & & & & & \\
\hline & ZK596.2 & CK1 & Casein kinase & & & & & & \\
\hline
\end{tabular}

\section{Chronic effect only}

\begin{tabular}{|c|c|c|c|c|c|c|c|}
\hline \multirow{2}{*}{$\begin{array}{l}\text { Genetic } \\
\text { Loci' }\end{array}$} & \multirow{2}{*}{$\begin{array}{l}\text { Sequence } \\
\text { name }{ }^{1,2}\end{array}$} & \multirow{2}{*}{$\begin{array}{l}\text { Kinase } \\
\text { Group'1.2 }\end{array}$} & \multirow[t]{2}{*}{ Description' } & \multicolumn{2}{|c|}{$\begin{array}{c}\text { F1 } \\
\text { Adult }\end{array}$} & \multicolumn{2}{|c|}{$\begin{array}{c}\text { F2 } \\
\text { Adult }\end{array}$} \\
\hline & & & & $+24 \mathrm{hr}$ & $+48 \mathrm{hr}$ & $+24 \mathrm{hr}$ & $+48 \mathrm{hr}$ \\
\hline atm-1 & Y48G1BL.2 & Atypical & Protein kinase ATM/Tel1 & & & & \\
\hline cdk-2 & K03E5.3 & GMGC & Protein kinase PCTAIRE & & & $\cdot$ & $\cdot$ \\
\hline daf-4 & C05D2.1 & TKL & Transforming growth factor beta receptor & & & & \\
\hline gcy-3 & R134.1 & RGC & Natriuretic peptide receptor & & & & \\
\hline gsk-3* & Y18D10A.5 & GMGC & Glycogen synthase kinase-3 & & & $\cdot$ & $\cdot$ \\
\hline ire-1 & C41C4.4 & Other & Inositol-requiring 1 protein kinase & & & & \\
\hline mig-15 & ZC504.4 & STE & Traf2- and Nck, GCK family & & & & \\
\hline pink-1 & EEED8.9 & Other & BRPK/PTEN-induced protein kinase & & & & \\
\hline riok-1 & M01B12.5 & Atypical & RIO kinase & & & & \\
\hline rskn-2 & C54G4.1 & ACG & Ribosomal protein S6 kinase & & & & \\
\hline$t / k-1^{*}$ & C07A9.3 & Other & Tousled kinase & & $\cdot$ & $\cdot$ & $\cdot$ \\
\hline wts-1 & T20F10.1 & ACG & Warts/lats-like serine threonine kinase & & & & $\cdot$ \\
\hline & $\mathrm{C} 29 \mathrm{H} 12.5$ & Other & & & & & \\
\hline & F09C12.2 & GMGC & Mitogen-activated protein kinase & & & & \\
\hline & F59A6.4 & CK1 & Casein kinase & & & & \\
\hline & Y50D4B.6 & TK-RTK & Growth factor receptor tyrosine kinase & & & & \\
\hline
\end{tabular}

${ }^{1}$ wormbase release WS232

${ }^{2}$ Manning G et al., 2005 Wormbook

Figure $\mathbf{3}$ (See legend on next page.) 
(See figure on previous page.)

Figure 3 Kinases that appear to be required for normal sarcomere structure. (A) Sample images of GFP labelled sarcomeres showing normally aligned sarcomeres in control, non-RNAi treated, PJ727 animal (left) and RNAi treated animals showing sarcomere structure defects. RNAi treatments are indicated in the lower right corner. Scale bars represent $20 \mu \mathrm{m}$. (B) Kinases identified as required for maintenance of normal sarcomere structure in adult muscle. Indicated RNAi treatments were conducted chronically and followed up acutely and scored for loss of sarcomere organization, see materials and methods. Displayed are scoring data for each time point $(n=20-30)$. Green indicates sarcomeres not appreciably different from controls. Red indicates that at least $25 \%$ of scored animals displayed disrupted sarcomere structure versus controls. Dark red indicates that at least 50\% of scored animals displayed disrupted sarcomere structure versus controls. (C) Kinases identified as required for normal sarcomere structure. RNAi treatments were conducted and scored as in (B) however the listed treatments produced a defect in the chronic screen but not the acute screen. - Indicates lack of data for a given time point. ${ }^{*}$ Indicates a treatment was classed as producing a lack of progeny in this screen.

protein degradation within C. elegans muscle [18] we focused on epistasis testing the genes identified in the protein degradation screen (Figure 1) against the known signalling pathways. In C. elegans muscle, presumptive autophagic degradation is controlled by the balance between constitutive, autocrine fibroblast growth factor receptor-Ras-Raf-MAPK signalling [34,35] and insulin growth factor receptor-PI3K-Akt-Raf signalling [22]. As with past studies we used unc-51, which encodes Autophagy-related1 (Atg1) [36], mutants to block autophagic protein degradation and we also used mutations in $m p k-1$, which encodes mitogen activated protein kinase (MAPK) [37], and daf-18, which encodes phosphatase and tensin homolog kinase [38], to map kinases required to prevent cytosolic protein degradation to activation of the autophagic signalling pathways in $C$. elegans. Proteasomal degradation appears to be controlled by plasma membrane polarization [12] and increased degradation by this system can be observed in response to starvation [17], denervation [39], and neurodegeneration [40]; as with past studies we used the proteasome inhibitor MG132 to block any degradation which required proteasomal activity [39].

For 21 of 48 kinases, $\beta$-galactosidase degradation was suppressed in the unc-51 and mpk-1 mutant strains suggesting that close to half of the kinases for which knockdown triggered muscle protein degradation are causing increased MPK-1 mediated autophagic protein degradation (Figure 5). To confirm autophagy was triggered by knockdown of each of the 21 kinases, we examined the accumulation of autophagic vesicles in response to knockdown in animals expressing GFP fused to the autophagic vesicle marker LGG-1 [36]. As shown in Figure 6, a significant increase in autophagic vesicles was observed in response to knockdown of each of these 21 genes $(\mathrm{p}<.0001$, one way ANOVA, GraphPad Prism). These results suggest that autophagic protein degradation is the proteolytic mechanism most commonly triggered by decreased expression of an individual kinase. Consistent with this, knockdown of only 6 kinases appeared to trigger proteasome-mediated degradation as evidenced by lack of degradation in the MG132 treatment condition. Two of these kinases, IRE-1 and PEK-1, are well conserved regulators of the endoplasmatic reticulum unfolded protein response which modulates both autophagic and proteasomal degradation. For 21 of the 48 kinases, $\beta$-galactosidase degradation was suppressed in daf-18 animals suggesting that knockdown of these kinases alters signalling in an insulinmediated pathway. The majority of these kinases also require MPK-1 and UNC-51, which is therefore consistent with past studies of signalling networks controlling protein degradation in C. elegans muscle. Included in this group are $s g k-1$ [21], gsk-3 [20] and the gene that encodes AMPactivated protein kinase [41], each of which is already known to be part of insulin-mediated control of protein homeostasis in other species. Additionally, 10 kinases appeared to trigger an as yet unidentified proteolytic mechanism as $\beta$-galactosidase degradation upon RNAi knockdown was not suppressed in the mutants or in MG132 treated animals. One of these genes is pat-4 for which calpains have recently been demonstrated to be the regulated protease [15]. While future study may uncover the details of the other potentially novel mechanisms, it is interesting that autophagy was triggered in response to roughly half of the kinase knockdowns in C. elegans.

\section{Discussion}

We have used RNAi to knock down the vast majority of the $C$. elegans kinome to examine the kinome requirement for establishing and maintaining sub-cellular processes within muscle. The use of $C$. elegans and RNAi has allowed us to define a preliminary in vivo functional kinome requirement for muscle which currently remains technically and economically challenging to establish in rodents and infeasible in human subjects. The evolutionary distance between the C. elegans and the human kinome suggests that not all results obtained in this study will be relevant to man and that there are some important kinases that we have not studied as they do not exist in C. elegans. However, our identification of kinases as required for normal subcellular processes in C. elegans muscle that are already known to regulate the same subcellular process(es) in mammals, suggests that some, if not many, of our results will be relevant to higher metazoans. Similarly, while our use of RNAi by 


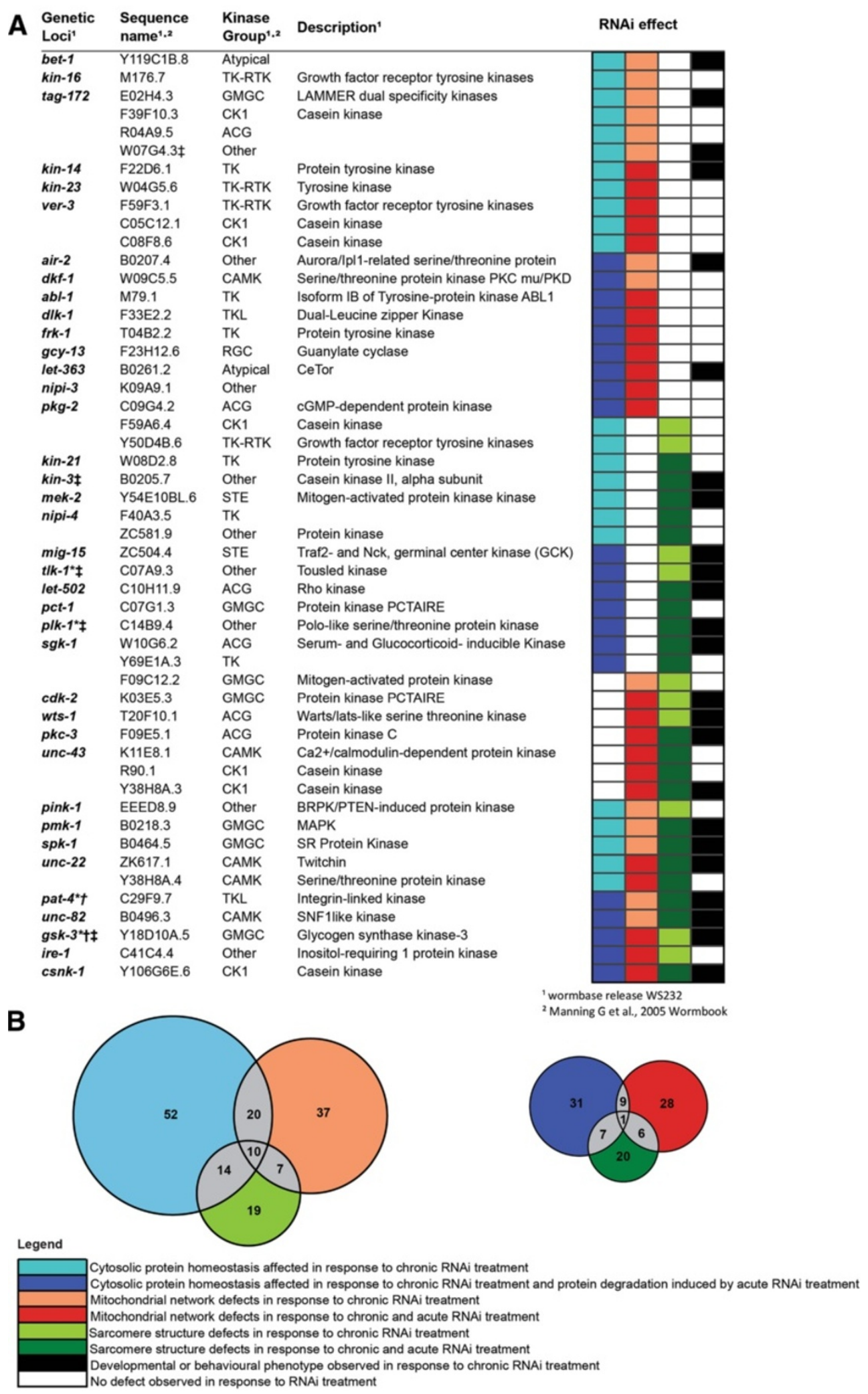

Figure 4 (See legend on next page.) 


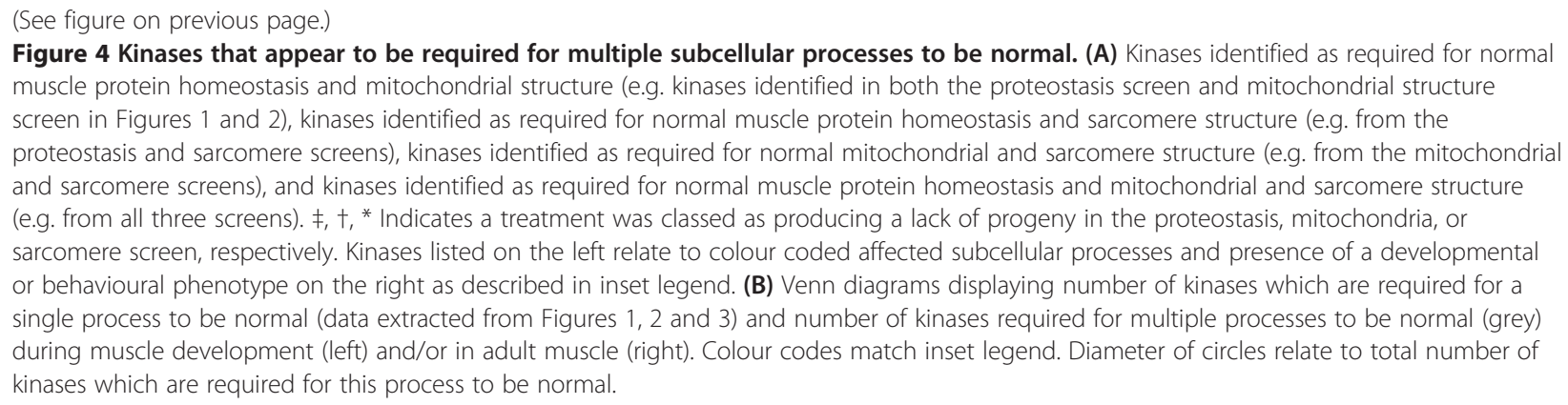

feeding has allowed us to define a preliminary in vivo functional kinome requirement for muscle, our use of this single method will almost certainly have caused us to overlook certain kinases. For example, RNAi by feeding does not produce a reproducible quantitative knockdown from animal to animal [42,43]. Thus, negative results and quantitative differences in defects in response to RNAi against different genes are not interpretable, as it is experimentally challenging to demonstrate quantitative knockdown in the same worm that is scored for subcellular defects and economically not feasible on the scale of the work reported here. Similarly, as the knockdowns occur in the whole animal it is not possible to definitively conclude if it is the knockdown of the targeted gene or another gene that is producing the observed defect nor is it possible to conclude if it is the knockdown in muscle, another tissue, or both that is producing the observed defect. Clearly future studies in kinase gene mutants are required, as are demonstrations of the tissue(s) in which each kinase is required for establishment and/or maintenance of muscle homeostasis. The recent availability of knockouts for most of the $C$. elegans kinome [44] should facilitate such future studies.

Our approach of observing several sub-cellular processes allowed us to analyse differences in the kinome requirement for multiple subcellular processes. For each of the processes studied there appear to be many more specific kinases required than kinases required for multiple processes to be normal within muscle. Thus, it does not appear to be the case that for the majority of the kinome disruption of any one individual kinase results in complete loss of cellular homeostasis. Our data also show that the two general cellular processes, cytosolic protein homeostasis and mitochondrial dynamics, appear to be more frequently affected by kinase RNAi knockdown than the muscle specific process of assembly and maintenance of sarcomeres. This raises the question whether there has been more frequent evolutionary selection for kinases required for general, metabolic processes over those required for other, more specialized cellular processes. Similarly, our observations raise the question whether processes more heavily impacted by kinome knockdown, such as protein homeostasis, are more tolerant of dysregulation without catastrophic failure. If so, this might explain why only $31 \%$ of defects in cytosolic protein homeostasis resulted in overall defects in behaviour or development in comparison to $48 \%$ of defects in sarcomeres. Together these observations suggest that further analysis of sub-cellular phenotypes or conditional phenotypes should allow assignment of putative function to the entire kinome of C. elegans.

Our use of chronic and acute RNAi screens revealed that the majority of kinases appeared to be required for the same subcellular processes during development as in terminally differentiated cells. This observation suggests that a large number of kinases that influence development continue to have an important function in the biology of fully differentiated cells; it may be that cellular regulatory networks are established during development. While it remains to be seen if the kinases regulate development and physiology and do so via identical mechanisms, the observation of conserved effects of knockdown during development and in fully differentiated muscle suggests that candidate drug targets could be selected based upon known roles of genes in the development of tissues of interest.

It remains to be seen if our findings are general features of the kinome in tissues outside of muscle but our identification of kinases that were already known to ubiquitously control protein homeostasis and mitochondrial dynamics suggests that at least some of the kinases identified are likely to affect these processes in other tissues. Additionally, as insulin/insulin growth factor receptor is a general controller of cell size, presumably as the result of MAPK dependent control of the overall rate of translation [45], our observation that functional MAPK is required to produce protein the degradation observed in response to knockdown of most kinases suggests that our observations may be not specific to muscle.

\section{Conclusions}

We identified 159 kinases for which RNAi knockdown induced defects in single or multiple sub-cellular processes in muscle. Some of the identified genes were already 


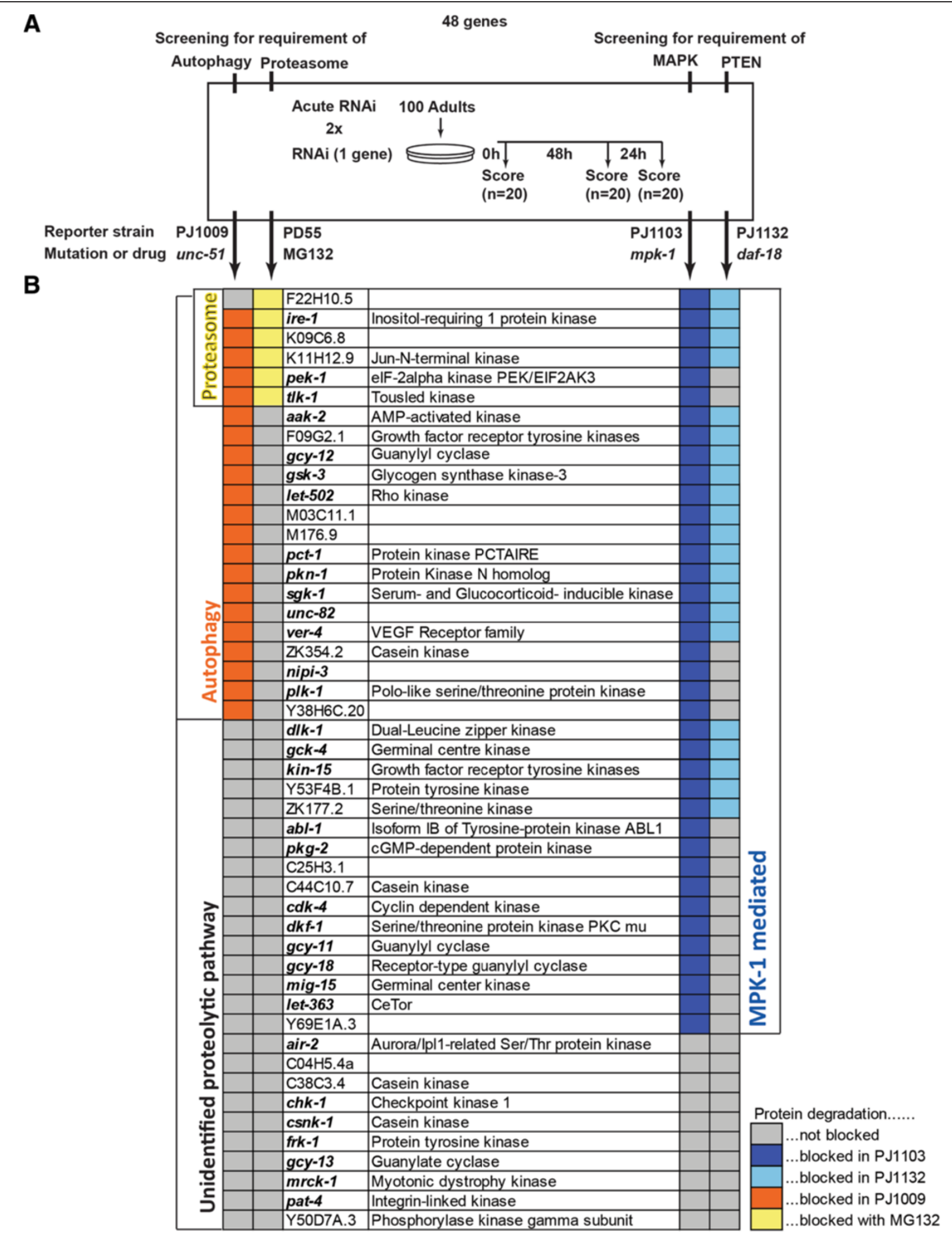

Figure $\mathbf{5}$ (See legend on next page.) 


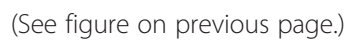

known to regulate the distinct sub-cellular processes that we also identified and therefore support the validity of this study. Most of the genes identified are new requirements for subcellular processes examined. For 51 of the identified genes no behavioural or developmental phenotype had previously been reported in functional genomics screens. Thus, our results provide measurable phenotypes to enable more detailed analyses of specific kinases that previously could not be studied in vivo and bring the portion of the $C$. elegans kinome that has a known function close to $75 \%$. Lastly, our results may have application to clinical conditions associated with loss of muscle homeostasis. For example, 33\% of kinases identified as required for $C$. elegans muscle homeostasis have human orthologues expressed in muscle (Additional file 1). Thus, some of these kinases may serve as the intramuscular transducers of known extramuscular factors that control muscle homeostasis. In this context, it is interesting to note that MAPK appears to be a central regulator of muscle protein degradation in C. elegans and the classical MAPK, extracellular-signal regulated kinase (ERK) is known to be functional in adult human muscle [46].

\section{Materials and methods}

\section{Nematode handling and strains utilized}

Nematode strains were maintained and grown at $20^{\circ} \mathrm{C}$ using Escherichia coli strain OP50 as a food source. Strains used were CB5600 (ccIs4251 I; him-8(e1489) IV), CC25 (pink-1 (tm1779) II), CC46 (ccIs4251 I; pink-1(tm1779) II; him-8(e1489) IV), PD55 (ccIs55 V), PJ727 (jIs01; ccIs55 V), PJ1009 (unc-51(e369), ccIs55 V), PJ1103 (mpk-1 (n2521) III; him-8 (e1489) cha-1(1182ts) IV; ccIs55 V), PJ1132 (daf-18 (e1375) IV; ccIs55 V), and KAG146 (kagEx12 (pKG169 (pdyc-1S:::fp::lgg-1) + pCFJ190(pmyo-2::mcherry) + pBSC)). pink-1 mutant strains were constructed using standard techniques [47], with the presence of pink-1 homozygotes confirmed by PCR (primers forward 5 ' tcattaggatctcgcttgag; reverse $5^{\prime}$ agcctcgggcttattaagga).

\section{Identification and source of RNAi clones utilized}

The global list of C. elegans kinases [5] was used to search for RNAi bacterial feeding clones previously utilized to determine the effect of knockdown of roughly each gene in the genome upon development and behaviour [6,7]. These identified clones were obtained from Source BioScience (Nottingham, UK). Additionally, a clone against let-363 was obtained from the University of Colorado [48]. After sequence verifying all positive results from our screen, we identified that previously utilized RNAi constructs were available for 397 kinase-encoding genes, which comprised 91\% of the C. elegans kinome; clone names beginning with a roman numeral arise from the Ahringer $C$. elegans RNAi library [6] while clones names beginning with an Arabic number arise from the Vidal ORF RNAi library [7] (Additional file 1).

\section{Quality control of our RNAi screens}

A schematic of how the three screens were performed is provided (Figure 7). RNAi using bacterial clones grown as described [6] was performed with both chronic and acute RNAi experiments as described previously [12]. A detailed technical description of the strengths, limitations, and caveats to interpretation of results from this screening methodology is available elsewhere [43].

We used RNAi against $u n c-112$ as a positive control as RNAi unc-112 has been shown to produce a developmental, behavioural, muscle protein degradation, mitochondrial, and sarcomere defect [15]. Each of the three screens was run in parallel such that the same genes were assessed in the same week, typically 20 genes/week. In cases where the positive control did not provide an abnormal phenotype in each of the screens the entire batch of genes was rerun with an unc-112 positive control.

We used previously utilized RNAi constructs so that we could directly compare our results for developmental phenotypes with those of others who previously utilized the same RNAi construct as a quality control measure. The false positive rate for developmental and behavioural phenotypes observed in response to RNAi by feeding in C. elegans is $<1 \%$, thus thresholds were set for ease of scoring. Developmental phenotypes were recorded if at least $20 \%$ of worms on the RNAi seeded plate showed a phenotype and also if the same phenotype was observed 


\section{A Autophagic vesicle visualisation}
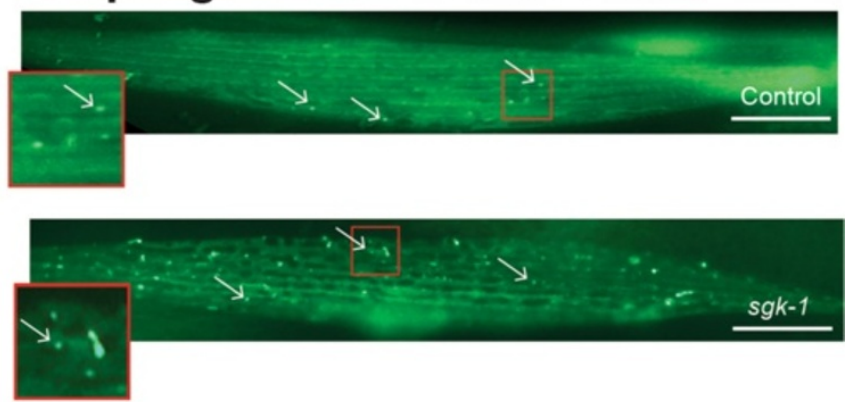

B Autophagic vesicle quantification

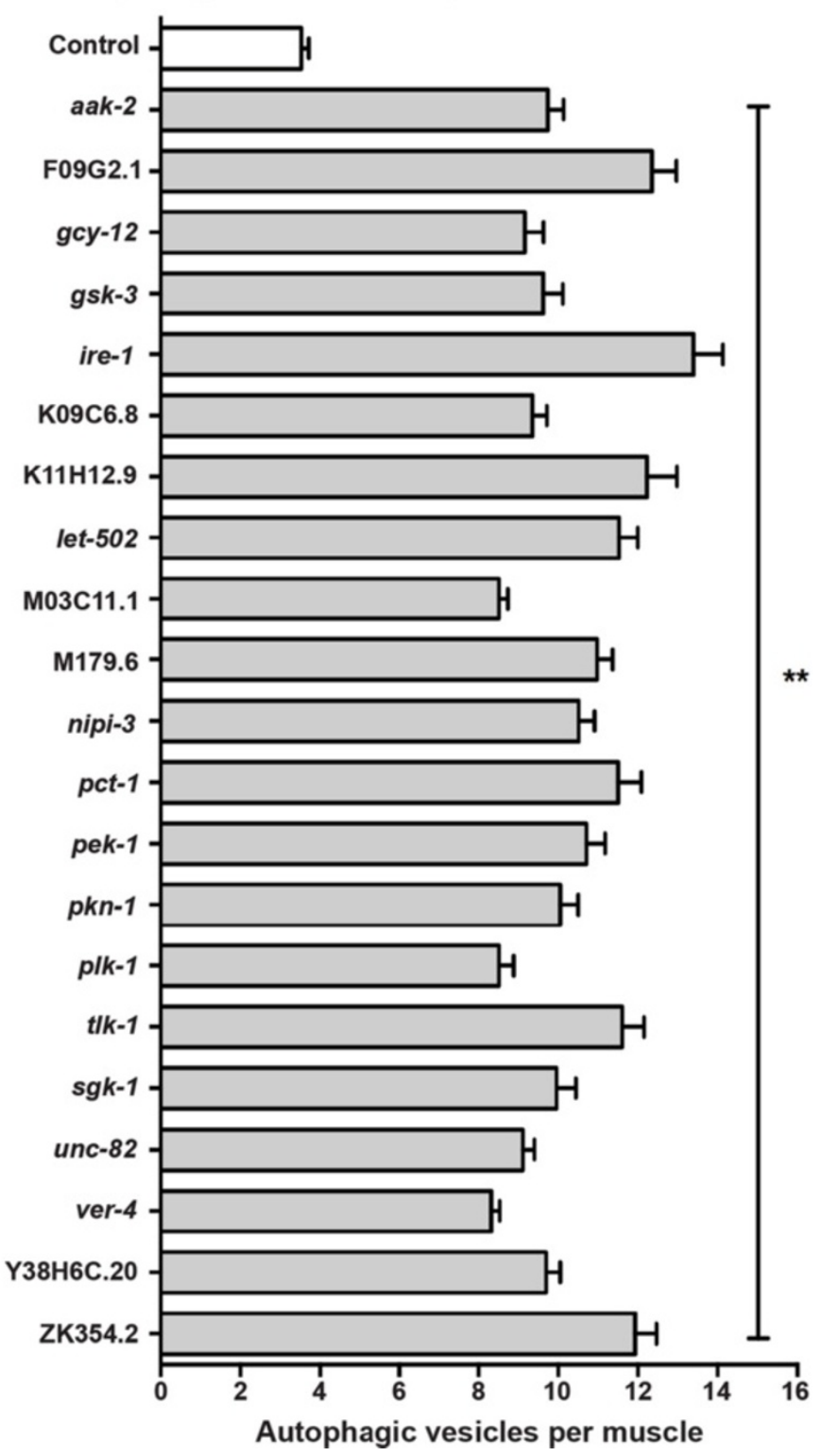

Figure 6 (See legend on next page.) 
(See figure on previous page.)

Figure 6 Increased autophagic vesicles are present in muscles following knockdowns appear to trigger autophagy. (A) Sample images of GFP labelled autophagic vesicles showing normally low levels in a control RNAi treated KAG146 animal (left) and an experimental RNAi treated animal showing increased vesicles. RNAi treatment is indicated in the lower right corner. Scale bars represent 20 um. (B) Each of the 21 kinase knockdowns that were identified as requiring autophagy to produce increased protein degradation displayed an increase in autophagic vesicles following 24 hours of acute RNAi treatment. Three independent experiments were performed ( $n=20$ each). Error bars represent standard error of measurement. ${ }^{* *} p<0.0001$, one way ANOVA.

in both generations, even in fewer than $10 \%$ of total worms (NB there was no similar change in threshold in the sub-cellular phenotype analyses). Developmental/behavioural phenotypes scored were: Unc (uncoordinated movement), Rol (rolling movement), Bmd (abnormal body morphology), Dpy (short fat appearance), Pvl (protrusion from the vulva), Rup (rupture from the vulva), Ste (sterile), Egl (egg laying defective), Emb (embryonic lethal) and Gro (long period of development and/or growth arrest). For a complete list of phenotypic results see Additional file 1. Comparison of phenotypes from our study to previously published phenotypes were made using www.wormbase. org. Comparison of the developmental and behavioural phenotypes we observed in response to RNAi with past studies that utilized the same RNAi construct revealed a false negative rate of $4 \%$ (NB two-thirds of these produced a sub-cellular defect in one or more of our screens), a divergence in phenotype observed of $2 \%$, and a first observation of a phenotype using the RNAi construct for $13 \%$ of genes studied. These figures are consistent with another recent study of the efficacy of the method we chose to employ [12] and are an improvement upon the roughly $30 \%$ false negative rate typically reported for RNAi by feeding in C. elegans. A detailed discussion of why our false negative rate is lower and our first discovery of function rate is higher than past studies as well as other technical details of improving results from RNAi screens can be found elsewhere [43].

All RNAi feeding clones for which a sub-cellular defect in muscle was scored as positive were sequence verified using Source BioScience LifeScience's Bugs2Bases service or using Source BioSciences' sequence verified clone service. In order to maximize usable returned sequence data, a combination of three primers were utilised separately for each clone: C.elegans RNAi F from the Source BioScience library, forward $5^{\prime}$ ggagaccggcagatctgata, and reverse $5^{\prime}$ ggcctcttcgctattacgc. Sequence data was analysed using

\section{A Chronic RNAi}

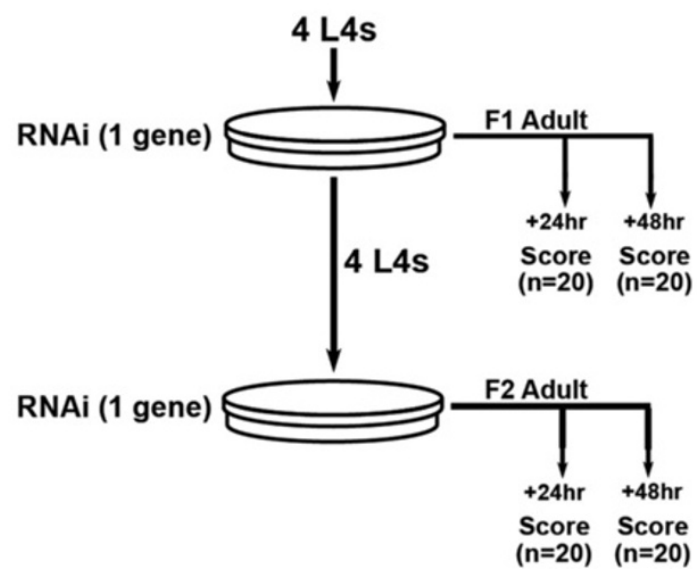

\section{B Acute RNAi}

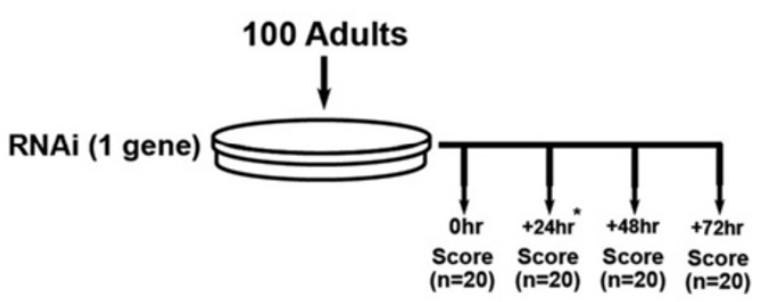

Figure 7 Systematic identification of kinases required for normal sub-cellular processes in muscle. Three parallel screens using RNAi feeding clones against 397 kinase-encoding genes were performed. Screens were run in parallel on the same genes, typically 20 per week. In each screen, all genes were assessed for the effect of RNAi upon a single sub-cellular process within muscle (using a different transgenic reporter in each screen). (A) All genes were assessed for the effect of chronic, multi-generational RNAi knockdown. PD55 was used for the proteostasis screen, CB5600 for the mitochondrial network structure screen, and PJ727 for the sarcomere structure screen. Upon reaching adulthood, F1 or F2 progeny were observed on two consecutive days using light microscopy after staining for $\beta$-galactosidase in the proteostasis screen or epifluorescence microscopy for the mitochondrial or sarcomere screens. (B) In each screen, identified genes and treatments that resulted in a lack of progeny were assessed for the effect of acute, single generation RNAi knockdown in age synchronized adults. Adult worms were observed using light microscopy after staining for $\beta$-galactosidase in the protein degradation screen or epifluorescence microscopy for the mitochondrial or sarcomere screen (to confirm normal baselines) and then allowed to grow on RNAi plates for an additional 72 hours. Additional measurements were taken $24^{*}, 48$, and 72 hours after being placed on RNAi plates. 24 hour measurements were only taken in the protein degradation screen. 
4Peaks (version 1.7.2) software and entered into NCBI $C$. elegans BLAST for confirmation of correct sequence.

\section{Assessment of proteostasis, proteolysis, mitochondrial network structure, and sarcomere structure via transgenic reporter proteins}

Muscle-specific protein homeostasis and protein degradation was assessed using transgene ccIs55 (unc-54::lacZ), with histochemical staining for $\beta$-galactosidase activity as described [17]. The protein product of ccIs55 is continually synthesized throughout development and remains stable (e.g. is neither synthesized nor degraded) in the cytosol for the first 72-96 hours post adulthood in wild-type animals $[15,17,22,35,39]$. Thus, alterations in $\beta$-galactosidase activity observed in response to chronic RNAi indicate alterations in protein synthesis and/or degradation whereas alterations in response to acute RNAi applied to fully developed adults indicate activation of protein degradation alone.

Muscle-specific mitochondria and nuclei were assessed using transgene ccIs4251(Pmyo-3::MitGFP; Pmyo-3::NLS:: GFP-lacZ), with epifluorescence microscopy as described [12]. Note that observations and images were taken of live, non-immobilized animals. This was achieved by capturing images while the animal was still.

Sarcomere structures were assessed using transgene jIs01(myo-3::GFP) which produces a translational fusion of the full-length MYO-3 (myosin heavy chain A) gene to GFP, with epifluorescence microscopy as described [12]. Note that observations and images were taken of live, non-immobilized animals. This was achieved by capturing images while the animal was still.

\section{Scoring criteria and procedure for each of the RNAi screens}

Sub-cellular phenotypes scored in each of the three screens were: Cytosolic protein content (normal, abnormal), mitochondrial morphology (normal, abnormal), and sarcomere morphology (normal, abnormal); see Figures 1, 2 and 3, respectively, for examples of normal and abnormal sub-cellular phenotypes. In all cases abnormalities deemed minor (e.g. not appreciably different from RNAi control) were scored as normal. Observations were scored as abnormal if defects were observed in at least $25 \%$ of worms on the slide (NB this is a 5\% increase in threshold from the study [12] upon which this protocol is based). Defects, within an individual worm, were classed using the same thresholds as from the study upon which this protocol is based [12], as follows: i) cytosolic protein content: at least a $30 \%$ loss of stain (e.g. intensity viewed as light blue or absent in contrast to dark blue); ii) mitochondrial morphology: loss of at least $30 \%$ of the mitochondrial network in at least two muscle cells (e.g. loss of linear networks that was significant enough to be noticeable and different from control animals). iii) sarcomere morphology: at least 2 disorganized or broken arrays of sarcomeres in at least two muscle cells (e.g. loss of linear arrays of sarcomeres that was significant enough to be noticeable and different from control animals). All scoring was done manually using a Nikon H600L microscope.

For chronic RNAi exposures (Figure 7A), a defect had to be observed in any two of the four time points examined to be scored as positive. Genes for which lack of progeny prevented scoring were also scored as giving a defect for the purposes of further examination. Genes that were identified as affecting cytosolic protein content, mitochondrial structure, or sarcomere structure in chronically treated animals were then examined for effects of acute RNAi exposure.

For acute RNAi exposures (Figure 7B), a defect had to be observed at any two time points after introduction to RNAi, with particular attention to progressive loss of cytosolic protein between the 48 and 72 hour time points. The criteria for a positive score at a single time point are identical to those described for the chronic RNAi screens.

For all observations, 4-6 representative images were captured on a Nikon H600L microscope with a Nikon Digital Sight DS-Fi1 digital camera and proprietary software. At the end of all of the screens, these images were used to confirm the results from the screen. Additionally, at the end of all screens all images were reviewed by an independent observer to confirm or correct initial scoring. In cases of a discrepancy between the first and second individual scoring the images the last author manually reviewed the data and the two sets of scoring in order to reach a final scoring.

\section{Epistasis testing of identified genes against known protein degradation pathways}

Mutants and MG132 used for clustering identified genes to known proteolytic pathways/mechanisms were as described [12]. Acute RNAi experiments with these mutants were performed as described [12]. Degradation was scored as in acute RNAi treatments in two independent experiments; in case of discrepancy a third experiment was run.

\section{Assessment of autophagic vesicles via transgenic reporter protein}

Muscle-specific autophagic vesicles were assessed using transgene $k a g E x 12(p d y c-1 S:: g f p:: \operatorname{lgg}-1)$, with epifluorescence. Transgenic animals were synchronised and subject to the acute RNAi protocol with scoring occurring at 24 hours post introduction to RNAi clone or a control clone lacking a targeted sequence. Autophagic vesicles were quantified within the two body wall muscles that visually appeared to contain the greatest number of 
vesicles. This was repeated in a total of 60 animals per RNAi treatment with 20 animals per experiment and each experiment run three times. Two or three RNAi clones with a separate control clone were analysed at once.

\section{Statistics}

All statistical analysis was undertaken utilizing GraphPad Prism (GraphPad Software, Inc., La Jolla, CA, USA). For assessment of distributions of data being significantly different from a normal distribution, $x^{2}$ analysis was used. For assessment of tested RNAi clone autophagic vesicle data being significantly different from control RNAi clone, one-way ANOVA with Dunnett's multiple comparison test was used.

\section{Additional file}

\section{Additional file 1: The following additional data are available with} the online version of the paper. A comprehensive list of genes screened, clones used, and results. Sheet "All genes screened" provides information and results for 397 genes screened including the bacterial clone used in this study, subcellular defects observed as indicated by colour coding (see legend at bottom) and developmental phenotypes observed, known human orthologues along with data on expression in human muscle. Sheet "no clones available" displays all genes for which an existing bacterial clone in the C. elegans RNAi library/Ahringer and C. elegans ORF-RNAi library/Nidal libraries was not available or for which sequencing suggests it may contain an incorrect target sequence.

\section{Abbreviations}

C. elegans: Caenorhabditis elegans; ERK: Extracellular-signal regulated kinase; GFP: Green fluorescent protien; MAPK: Mitogen activated protein kinase: PI3K: Phosphatidylinositide 3 Kinase; RNAi: RNA interference.

\section{Competing interests}

The authors declare that they have no competing interests.

\section{Authors' contributions}

SL, JJB and NJS designed the studies and analyzed the data. SL and JJB conducted the RNAi experiments. JJB and NJS conducted the sequence analysis. SL and NJS wrote the paper. All authors read and approved the final manuscript.

\section{Acknowledgements}

Our thanks to L.A. Jacobson (University of Pittsburgh) for useful discussions, the Mitani laboratory (Tokyo Women's Medical University) for providing the pink-1(tm 1779) mutant strain, and the Gieseler laboratory (Université Claude Bernard Lyon 1) for making and providing strain KAG146 prior to publication. This work was funded by the US NIH- NIAMS (AR-054342). J.J.B. was funded by an MRC doctoral training award (J500495)

Received: 19 February 2013 Accepted: 15 September 2013 Published: 23 September 2013

\section{References}

1. Jin J, Pawson T: Modular evolution of phosphorylation-based signalling systems. Philos Trans R Soc Lond B Biol Sci 2012, 367(1602):2540-2555.

2. Cohen $P$ : The regulation of protein function by multisite phosphorylation-a 25 year update. Trends Biochem Sci 2000, 25(12):596-601.

3. Fedorov O, Muller S, Knapp S: The (un)targeted cancer kinome. Nat Chem Biol 2010, 6(3):166-169.
4. Piano F: C. elegans network biology: a beginning (August 21, 2006). In WormBook. Edited by The C. elegans Research Community, WormBook. doi:10.1895/wormbook.1.118.1. http://www.wormbook.org.

5. Manning G: Genomic overview of Protein Kinases (December 13, 2005) In WormBook. Edited by The C. elegans Research Community, WormBook. doi:10.1895/wormbook.1.60.1. http://www.wormbook.org.

6. Kamath RS, Fraser AG, Dong Y, Poulin G, Durbin R, Gotta M, Kanapin A, Le Bot N, Moreno S, Sohrmann M, et al: Systematic functional analysis of the Caenorhabditis elegans genome using RNAi. Nature 2003, 421(6920):231-237.

7. Rual JF, Ceron J, Koreth J, Hao T, Nicot AS, Hirozane-Kishikawa T, Vandenhaute J, Orkin SH, Hill DE, van den Heuvel S, et al: Toward improving Caenorhabditis elegans phenome mapping with an ORFeome-based RNAi library. Genome research 2004, 14(10B):2162-2168.

8. Chen N, Harris TW, Antoshechkin I, Bastiani C, Bieri T, Blasiar D, Bradnam K, Canaran P, Chan J, Chen CK, et al: WormBase: a comprehensive data resource for Caenorhabditis biology and genomics. Nucleic Acids Res 2005, 33(Database issue):D383-D389.

9. Glass $D$, Roubenoff R: Recent advances in the biology and therapy of muscle wasting. Ann N Y Acad Sci 2010, 1211:25-36.

10. Shaye DD, Greenwald I: OrthoList: a compendium of $C$. elegans genes with human orthologs. PLoS One 2011, 6(5):e20085.

11. Uhlen $M$, Oksvold $P$, Fagerberg $L$, Lundberg $E$, Jonasson $K$, Forsberg $M$ Zwahlen M, Kampf C, Wester K, Hober S, et al: Towards a knowledgebased Human Protein Atlas. Nat Biotechnol 2010, 28(12):1248-1250.

12. Shephard F, Adenle AA, Jacobson LA, Szewczyk NJ: Identification and functional clustering of genes regulating muscle protein degradation from amongst the known C. elegans muscle mutants. PLoS One 2011, 6(9):e24686.

13. Meissner B, Warner A, Wong K, Dube N, Lorch A, McKay SJ, Khattra J, Rogalski T, Somasiri A, Chaudhry I, et al: An integrated strategy to study muscle development and myofilament structure in Caenorhabditis elegans. PLOS Genet 2009, 5(6):e1000537.

14. Schnorrer F, Schonbauer C, Langer CC, Dietzl G, Novatchkova M, Schernhuber K, Fellner M, Azaryan A, Radolf M, Stark A, et al: Systematic genetic analysis of muscle morphogenesis and function in Drosophila. Nature 2010, 464(7286):287-291.

15. Etheridge T, Oczypok EA, Lehmann S, Fields BD, Shephard F, Jacobson LA, Szewczyk NJ: Calpains Mediate Integrin Attachment Complex Maintenance of Adult Muscle in Caenorhabditis elegans. PLoS Genet 2012, 8(1):e1002471

16. Sandri M: Signaling in muscle atrophy and hypertrophy. Physiology (Bethesda) 2008, 23:160-170.

17. Zdinak LA, Greenberg IB, Szewczyk NJ, Barmada SJ, Cardamone-Rayner M, Hartman JJ, Jacobson LA: Transgene-coded chimeric proteins as reporters of intracellular proteolysis: starvation-induced catabolism of a lacZ fusion protein in muscle cells of Caenorhabditis elegans. $J$ Cell Biochem 1997, 67(1):143-153.

18. Lehmann S, Shephard F, Jacobson LA, Szewczyk NJ: Integrated control of protein degradation in muscle. Worm 2012, 1(3):141-150.

19. Lo TW, Bennett DC, Goodman SJ, Stern MJ: Caenorhabditis elegans fibroblast growth factor receptor signaling can occur independently of the multi-substrate adaptor FRS2. Genetics 2010, 185(2):537-547.

20. McColl G, Killilea DW, Hubbard AE, Vantipalli MC, Melov S, Lithgow GJ: Pharmacogenetic analysis of lithium-induced delayed aging in Caenorhabditis elegans. J Bio/ Chem 2008, 283(1):350-357.

21. Hertweck M, Gobel C, Baumeister R: C. elegans SGK-1 is the critical component in the Akt/PKB kinase complex to control stress response and life span. Dev Cell 2004, 6(4):577-588.

22. Szewczyk NJ, Peterson BK, Barmada SJ, Parkinson LP, Jacobson LA: Opposed growth factor signals control protein degradation in muscles of Caenorhabditis elegans. EMBO J 2007, 26(4):935-943.

23. Shen $X$, Ellis RE, Lee $K$, Liu CY, Yang K, Solomon A, Yoshida H, Morimoto R, Kurnit DM, Mori $\mathrm{K}$, et al: Complementary signaling pathways regulate the unfolded protein response and are required for $C$. elegans development. Cell 2001, 107(7):893-903.

24. Chan DC: Fusion and Fission: Interlinked Processes Critical for Mitochondrial Health. Annu Rev Genet 2012, 46:265-287.

25. Fire A, Xu S, Montgomery MK, Kostas SA, Driver SE, Mello CC: Potent and specific genetic interference by double-stranded RNA in Caenorhabditis elegans. Nature 1998, 391(6669):806-811. 
26. Clark IE, Dodson MW, Jiang C, Cao JH, Huh JR, Seol JH, Yoo SJ, Hay BA, Guo $\mathrm{M}$ : Drosophila pink1 is required for mitochondrial function and interacts genetically with parkin. Nature 2006, 441(7097):1162-1166

27. Cribbs JT, Strack S: Reversible phosphorylation of Drp1 by cyclic AMPdependent protein kinase and calcineurin regulates mitochondrial fission and cell death. EMBO Rep 2007, 8(10):939-944.

28. Qadota H, Benian GM: Molecular structure of sarcomere-to-membrane attachment at M-Lines in C. elegans muscle. J Biomed Biotechnol 2010, 2010:864749.

29. Sparrow J, Hughes SM, Segalat L: Other model organisms for sarcomeric muscle diseases. Adv Exp Med Biol 2008, 642:192-206.

30. Fostel $J$, Benner Coste $L$, Jacobson LA: Degradation of transgene-coded and endogenous proteins in the muscles of Caenorhabditis elegans. Biochem Biophys Res Commun 2003, 312(1):173-177.

31. Mackinnon AC, Qadota H, Norman KR, Moerman DG, Williams BD: C. elegans PAT-4/ILK functions as an adaptor protein within integrin adhesion complexes. Curr Biol 2002, 12(10):787-797.

32. Benian GM, Tinley TL, Tang X, Borodovsky M: The Caenorhabditis elegans gene unc-89, required fpr muscle M-line assembly, encodes a giant modular protein composed of $\mathrm{lg}$ and signal transduction domains. J Cell Biol 1996, 132(5):835-848.

33. Benian GM, Kiff JE, Neckelmann N, Moerman DG, Waterston RH: Sequence of an unusually large protein implicated in regulation of myosin activity in C. elegans. Nature 1989, 342(6245):45-50.

34. Szewczyk NJ, Peterson BK, Jacobson LA: Activation of Ras and the mitogen-activated protein kinase pathway promotes protein degradation in muscle cells of Caenorhabditis elegans. Mol Cell Biol 2002, 22(12):4181-4188.

35. Szewczyk NJ, Jacobson LA: Activated EGL-15 FGF receptor promotes protein degradation in muscles of Caenorhabditis elegans. EMBO J 2003, 22(19):5058-5067.

36. Melendez A, Talloczy Z, Seaman M, Eskelinen EL, Hall DH, Levine B: Autophagy genes are essential for dauer development and life-span extension in C. elegans. Science 2003, 301(5638):1387-1391.

37. Lackner MR, Kornfeld K, Miller LM, Horvitz HR, Kim SK: A MAP kinase homolog, mpk-1, is involved in ras-mediated induction of vulval cell fates in Caenorhabditis elegans. Genes Dev 1994, 8(2):160-173.

38. Ogg S, Ruvkun G: The C. elegans PTEN homolog, DAF-18, acts in the insulin receptor-like metabolic signaling pathway. Mol Cell 1998 2(6):887-893.

39. Szewczyk NJ, Hartman JJ, Barmada SJ, Jacobson LA: Genetic defects in acetylcholine signalling promote protein degradation in muscle cells of Caenorhabditis elegans. J Cell Sci 2000, 113(Pt 11):2003-2010.

40. Estevez AO, Mueller CL, Morgan KL, Szewczyk NJ, Teece L, Miranda-Vizuete A, Estevez M: Selenium induces cholinergic motor neuron degeneration in Caenorhabditis elegans. Neurotoxicology 2012, 33(5):1021-1032.

41. Apfeld J, O'Connor G, McDonagh T, DiStefano PS, Curtis R: The AMPactivated protein kinase AAK-2 links energy levels and insulin-like signals to lifespan in C. elegans. Genes Dev 2004, 18(24):3004-3009.

42. Min K, Kang J, Lee J: A modified feeding RNAi method for simultaneous knock-down of more than one gene in Caenorhabditis elegans. Biotechniques 2010, 48(3):229-232

43. Lehmann S, Shephard F, Jacobson LA, Szewczyk NJ: Using Multiple Phenotype Assays and Epistasis Testing to Enhance the Reliability of RNAi Screening and Identify Regulators of Muscle Protein Degradation. Genes (Basel) 2012, 3(4):686-701.

44. Consortium TCeDM: Large-Scale Screening for Targeted Knockouts in the Caenorhabditis elegans Genome. G3 (Bethesda) 2012, 2(11):1415-1425.

45. Pause A, Belsham GJ, Gingras AC, Donze O, Lin TA, Lawrence JC Jr, Sonenberg N: Insulin-dependent stimulation of protein synthesis by phosphorylation of a regulator of 5'-cap function. Nature 1994, 371(6500):762-767

46. Drummond MJ, Fry CS, Glynn EL, Dreyer HC, Dhanani S, Timmerman KL, Volpi $E$, Rasmussen BB: Rapamycin administration in humans blocks the contraction-induced increase in skeletal muscle protein synthesis. J Physiol 2009, 587(Pt 7):1535-1546.

47. Brenner S: The genetics of Caenorhabditis elegans. Genetics 1974, 77(1):71-94.

48. Henderson ST, Bonafe M, Johnson TE: daf- 16 protects the nematode Caenorhabditis elegans during food deprivation. J Gerontol A Biol Sci Med Sci 2006, 61(5):444-460.

doi:10.1186/1478-811X-11-7

Cite this article as: Lehmann et al.: Knockdown of the $C$. elegans Kinome identifies Kinases required for normal protein Homeostasis, Mitochondrial network structure, and Sarcomere structure in muscle. Cell Communication and Signaling 2013 11:71.

\section{Submit your next manuscript to BioMed Central and take full advantage of:}

- Convenient online submission

- Thorough peer review

- No space constraints or color figure charges

- Immediate publication on acceptance

- Inclusion in PubMed, CAS, Scopus and Google Scholar

- Research which is freely available for redistribution
C Biomed Central 